\title{
BMJ Open Evaluation of IL-12RB1, IL-12B, CXCR-3 and IL-17a expression in cases affected by a non-healing form of cutaneous leishmaniasis: an observational study design
}

Mohammad Moafi, ${ }^{1}$ Hossein Rezvan, ${ }^{1}$ Roya Sherkat, ${ }^{2}$ Roya Taleban, ${ }^{2}$ Ali Asilian, ${ }^{3}$ Seyed Hamid Zarkesh Esfahani, ${ }^{4}$ Mohammad Ali Nilforoushzadeh, ${ }^{5}$ Fariba Jaffary, ${ }^{3}$ Awat Feizi ${ }^{6}$

To cite: Moafi M, Rezvan H, Sherkat $\mathrm{R}$, et al. Evaluation of IL-12RB1, IL-12B, CXCR-3 and IL-17a expression in cases affected by a nonhealing form of cutaneous leishmaniasis: an observational study design. BMJ Open 2017;7:e013006. doi:10.1136/bmjopen-2016013006

- Prepublication history for this paper is available online. To view these files please visit the journal online (http://dx.doi.org/10.1136/ bmjopen-2016-013006).

Received 14 June 2016 Revised 10 October 2016 Accepted 23 December 2016

\section{CrossMark}

For numbered affiliations see end of article.

\section{Correspondence to}

Dr Hossein Rezvan; hosseinrezvanbas@gmail. com

\section{ABSTRACT}

Introduction: Seldom cutaneous leishmaniasis (CL) may present as a lasting and active lesion(s), known as a non-healing form of $\mathrm{CL}$ (NHCL). Non-functional type 1 T helper (Th1) cells are assumed the most important factor in the outcome of the disease. The present study aims to assess some molecular defects that potentially contribute to Th1 impairment in NHCL.

\section{Methods and analysis: This prospective} observational study will be implemented among five groups. The first and second groups comprise patients afflicted with non-healing and healing forms of $\mathrm{CL}$, respectively. The third group consists of those recovered participants who have scars as a result of $\mathrm{CL}$. Those participants who have never lived or travelled to endemic areas of leishmaniasis will comprise the fourth group. The fifth group comprises participants living in hyperendemic areas for leishmaniasis, although none of them have been afflicted by CL. The aim is to recruit 10 NHCL cases and 30 participants in each of the other groups. A leishmanin skin test (LST) will be performed to assess in vivo immunity against the Leishmania infection. The cytokine profile (interleukin (IL)-12p70, interferon (IFN)- $\gamma, C-X-C$ motif chemokine ligand (CXCL)-11 and IL-17a) of the isolated peripheral blood mononuclear cells (PBMCs) will be evaluated through ELISA. Real-time PCR will determine the C-X-C motif chemokine receptor (CXCR)-3 and IL-17a gene expression and expression of IL-12R $\beta 1$ will be assessed by flow cytometry. Furthermore, IL-12B and IL-12RB1 mutation analysis will be performed.

Discussion: It is anticipated that the outcome of the current study will identify IL-12B and IL-12RB1 mutations, which lead to persistent lesions of $\mathrm{CL}$. Furthermore, our expected results will reveal an association between NHCL and pro-inflammatory cytokines (IL-12p70, IFN- $\gamma$ IL-17a and CXCL-11), as well as CXCR-3 expression.

Ethics and dissemination: This study has been approved by a local ethical committee. The final results will be disseminated through peer-reviewed journals and scientific conferences.

\section{Strengths and limitations of this study}

- This is a prospective study that has not yet been carried out; it aims to assess the role of interleukin (IL)-12RB1 and IL-12B mutation in a nonhealing form of cutaneous leishmaniasis (NHCL).

- For the first time, this study design aims to assess C-X-C motif chemokine ligand (CXCL)-11 and IL-17a cytokines in patients afflicted by NHCL and the C-X-C motif chemokine receptor (CXCR)-3 gene expression.

- NHCL cases are rare; hence, we faced limitations in the number of cases affected by non-healing lesions of cutaneous leishmaniasis (CL).

\section{INTRODUCTION}

Leishmaniasis is considered to be a neglected tropical as well as an emerging and uncontrolled disease, which demonstrates highly variable clinical signs and symptoms. This disease is causing significant morbidity and mortality among 380 million susceptible individuals that are at risk in 98 countries. According to the WHO, the global incidence of visceral and cutaneous leishmaniasis (CL) varies from 200000 to 400000 and 700000 to 1200000 patients, respectively. ${ }^{1-3}$ CL mostly appears as singular or multiple lesions, which spontaneously heal within 2-10 months. However, CL seldom manifests as long-lasting and active Leishmania lesions for more than a few years. ${ }^{4-9}$

Much data has demonstrated that innate and acquired immunity is clearly involved in the outcome of the disease. ${ }^{10}$ According to the previously published articles regarding animal modelling, the clinical manifestation of the Leishmania infection is based on type 1 
$\mathrm{T}$ helper (Th1) and type $2 \mathrm{~T}$ helper (Th2) dichotomies. ${ }^{11}$ In fact, the induction and maintenance of a Th1 immune response are indispensable for Leishmania clearance and lesion healing. Hence, primary immunodeficiency deficiencies (PIDs), which impede interferon (IFN) $-\gamma$ production, probably predispose patients to intracellular pathogens such as Leishmania infection. ${ }^{12} 13$ Mutations in the interleukin (IL)-12RB1 and IL-12B genes lead to IL-12 receptor $\beta 1$ (IL-12ß1) and IL-12p40 deficiencies, respectively. All of these deficiencies impair IFN- $\gamma$ production, which potentially increases one's susceptibility to refractory Leishmaniasis. ${ }^{14}{ }^{15}$ For example, Sanal $e t \mathrm{al}^{16}$ reported a 5-year-old patient, whose natural killer and T cells did not express IL-12R $\beta 1$. This patient suffered from a refractory form of Kala Azar disease, which lasted about 6 months. ${ }^{16}$

IL-12p40 and IL-12Rß1 (CD-212) deficiencies may also lead to fewer Th17 cells. ${ }^{17}$ The Th17 lineage of T helper cells potentially provides protection against pathogenic intracellular organisms such as the Leishmania species. This explains why IL-17R knockout mice show an increased susceptibility to systemic Leishmania infections. ${ }^{18}{ }^{19}$ However, IL-17a knockout mice demonstrated attenuated Leishmania lesions. ${ }^{20}{ }^{21}$ Hence, the role of IL-17 during a Leishmania infection is poorly understood.

The Th1 subset of CD4 cells, as well as CD8 T cells, expresses C-X-C motif chemokine receptor 3 (CXCR-3) molecules, which recruit these cells in inflammatory lesions. Expression of the CXCR-3 gene is clearly regulated through T-bet, which is the major transcription factor of Th1 subset. ${ }^{22}$ Furthermore, it has been shown that CXCR-3 expression gives protection from intracellular parasites such as different Leishmania species. For example, BALB/c mice, which are genetically susceptible to Leishmania infection, cannot upregulate the CXCR-3 gene expression in response to Leishmania infections. ${ }^{23}$ Nevertheless, CXCL-11 chemokine, which is assumed as a major ligand of the CXCR-3 gene, can induce Th2-driven responses. ${ }^{24}$ Therefore, the precise roles of CXCR-3 and its major ligand in the Leishmania infection remain ambiguous.

Based on the previous studies, consanguinity can be assumed as a risk factor, contributing to the high prevalence of primary immunodeficiency diseases (PIDs). ${ }^{25}$ Furthermore, high levels of consanguinity, as well as PIDs, are documented in Iran. ${ }^{26-29}$ In addition, some reports document the existence of chronic or nonhealing leishmaniasis in Middle East countries. ${ }^{30-38}$ Hence, assessment of IL-12R $\beta 1$ and IL-12p40 deficiencies as well as CXCL-11 and IL-17a could describe new features of PIDs, which present as non-healing form of CL (NHCL). To the best of our knowledge, none of the researches implemented throughout the world have aimed to evaluate the possible physiopathological role of PIDs, which constitute NHCL.

\section{Methods and analysis}

This is a prospective observational study, which will evaluate in vitro and in vivo immune responses against the Leishmania infection. The study will be undertaken from July 2016 to September 2017 in the Acquired Immunodeficiency Research Center, Isfahan University of Medical Sciences (IUMS), Isfahan, Iran.

\section{Study groups}

This study comprises five different groups (table 1). The first group includes patients affected by healing lesions of CL. The second group includes patients affected by NHCL. Leishmania major causes NHCL when its cutaneous lesion lasts for $>1$ year. CL induced by $L$ tropica is considered as a non-healing form when its active lesion lasts for $>2$ years. NHCL generally does not respond to three courses of chemotherapy based on antimonials. In comparison, healing lesions of CL caused by $L$ major will heal with or without medical treatment in $<1$ year. In the case of $L$ tropica, healing lesions will be maximally cured in 2 years (with or without medical intervention). ${ }^{37} 38$ The third group includes individuals who have recovered from CL and have scars of leishmaniasis. CL in

\begin{tabular}{|c|c|c|c|c|}
\hline Group number & Active lesion* & Duration of lesion† & Scar of lesion¥ & History of living or travel§ \\
\hline 1 & + & $\begin{array}{l}\leq 1 \text { year in case of Leishmania major } \\
\leq 2 \text { years in case of } L \text { tropica }\end{array}$ & - & \pm \\
\hline 2 & + & $\begin{array}{l}>1 \text { year in case of } L \text { major } \\
>2 \text { years in case of } L \text { tropica }\end{array}$ & - & \pm \\
\hline 3 & - & $\begin{array}{l}\leq 1 \text { year in case of } L \text { major } \\
\leq \text { years in case of } L \text { tropica }\end{array}$ & + & \pm \\
\hline 4 & - & $\overline{N A}$ & - & - \\
\hline 5 & - & NA & - & + \\
\hline
\end{tabular}


these patients was previously confirmed through parasitological methods. The fourth group is comprised of healthy individuals who have not lived or travelled to endemic areas for leishmaniasis. The fifth group comprises individuals who have lived a minimum of 5 years in hyperendemic areas for CL. None of the participants in the last group have a clinical history of CL (table 1). Inclusion criteria are males and females who are: (1) 5-60 years of age, (2) without HIV infection and (3) without addiction. Exclusion criteria are: (1) pregnancy, (2) steroid intake, (3) diabetes, (4) hypersensitivity, (5) hypertension and (6) lactation.

\section{Sample size}

All available patients affected by NHCL (ie, $n=10$ ) will be recruited; however, for statistical power analysis's purposes, three controls in each of the four remaining groups will be considered, resulting in a 1:3 prospective follow-up study. ${ }^{39}$ Accordingly, 10 patients afflicted with NHCL and 30 participants in each of the four control groups will be investigated.

\section{Leishmania diagnosis}

Direct smear and parasite culture will be applied to verify suspected leishmaniasis in patients. For this, the active lesions of the suspected patients will be cleaned and disinfected by the use of povidone-iodine and ethanol $70 \%$. Afterwards, cutaneous scraping will be made from the lesion base by a sterile surgical blade (no. 10). Serosa and skin tissue obtained through scraping will be applicable for direct smear and Leishmania culture. $^{40}$

\section{Direct smear}

For a microscopic diagnosis of Leishmania infection, two thin smears will be prepared for every patient. Smear fixation through absolute methanol (for $30 \mathrm{~s}$ ) will be preceded by drying in air. Afterwards, the smear will be stained with Giemsa (10\%) for $30 \mathrm{~min}$. The smears will be assumed to be positive if amastigote forms of Leishmania species can be detected in macrophages, or out of the cells through a light microscope (magnification $1000 \times) .{ }^{40}$

\section{Leishmania culture}

All of the specimens, which include negative and positive smears, will be evaluated by the culture method. For this aim, the extracted tissue and serosa will be transferred to tubes containing biphasic Novy-Nicol-Mac Neal $(\mathrm{NNN})$ medium $(6 \mathrm{~g} / \mathrm{L} \mathrm{NaCl}, 14 \mathrm{~g} / \mathrm{L}$ plain non-nutrient agar, $150 \mathrm{cc} / \mathrm{L}$ of rabbit defibrinated blood and up to $1200 \mathrm{~mL} \mathrm{H}_{2} \mathrm{O}$ ) in sterile conditions. ${ }^{40}$ The inoculated medium will be incubated at $26 \pm 1^{\circ} \mathrm{C}$ and its contents will be checked for promastigote forms of Leishmania species every 3 days. To enhance parasite proliferation, the cultivated parasites will be isolated and transferred to Roswell Park Memorial Institute 1640 medium (RPMI 1640) plus $20 \mathrm{U}$ penicillin (per $\mathrm{mL}$ ), $20 \mu \mathrm{g}$ of streptomycin (per $\mathrm{mL}$ ) and $10 \%$ fetal calf serum (FCS). The parasites will be incubated at $26 \pm 1^{\circ} \mathrm{C}$ for 4 weeks, while the liquid medium will be replaced every 3 days. The parasite proliferation will be assessed through an inverted light microscope (magnification $40 \times$ ). ${ }^{41}$

\section{Leishmania species identification}

We will spin $10 \mathrm{~mL}$ of medium, which contains proliferated promastigotes, at $400 \mathrm{~g}$ for $5 \mathrm{~min}$. Afterwards, we will resuspend and wash the pellets in $1 \mathrm{~mL}$ sterile phosphate buffer solution (PBS (Cytomatingen Co, Isfahan, Iran)) three times. ${ }^{42}$

\section{Nucleic acid extraction}

Leishmania pellets will be resuspended in $10 \mathrm{~mL}$ lysing buffer: $0.15 \mathrm{M}$ sodium chloride, 0.1 EDTA, $100 \mu \mathrm{g} / \mathrm{mL}$ proteinase $\mathrm{K}$ and $0.5 \%$ sodium dodecyl sulfate (SDS). This suspension will be incubated at $50 \pm 1^{\circ} \mathrm{C}$ for half an hour. The extraction will proceed further by pellet washing and resuspension: twice in phenol $(300 \mu \mathrm{L}$ every time) at $60^{\circ} \mathrm{C}$, once in phenol-chloroform-isoamyl alcohol (25:24:1) and once in chloroform-isoamyl alcohol (24:1). Extracted nucleic acid will be washed and collected by diethyle ether and ethanol, respectively. In all of the steps, the pellets will be formed through recentrifugation at $400 \mathrm{~g}$ for $15 \mathrm{~min} .{ }^{42}$

\section{Identification of Leishmania species through internal transcribed spacer-ribosomal DNA (ITS-rDNA)}

ITS-1, ITS-2 and 5.8s tracts, which form some parts of the ribosomal DNA (rDNA), could be efficiently exploited for the identification of the Leishmania species. For DNA amplification, forward (F:5/-CAACA CGCCGCCTCCTCTCT-3/) and reverse (R:5/-CCTCTCT TTTTTCNCTGTGC-3/) primers will be applied. ${ }^{42}$ Standard PCR will be implemented through a Qiagen PCR kit, in $50 \mu \mathrm{L}$ total volume for every sample, including $1 \times \mathrm{Q}$ solution, $2.5 \mathrm{mM} \mathrm{MgCl}_{2}, 1 \times$ standard PCR buffer, dNTPs $(200 \mathrm{mM}), 0.5 \mu \mathrm{M}$ of each primer $1 \mathrm{U}$ HotStarTaq Plus and 20-40 ng of genomic DNA. This concentration will be evaluated at $260 \mathrm{~nm}$ through spectrophotometry (Bio Photometer, Eppendorf, Germany). PCR amplification conditions will be: denaturation at $95^{\circ} \mathrm{C}$ for $5 \mathrm{~min}$ proceeded by 31 cycles of denaturation at $94^{\circ} \mathrm{C}$ for $30 \mathrm{~s}$, annealing at $60^{\circ} \mathrm{C}$ for $45 \mathrm{~s}$, extension at $72^{\circ} \mathrm{C}$ for $60 \mathrm{~s}$ and a final extension step at $72^{\circ} \mathrm{C}$ for 5 min. Positive controls will include nucleic acid extracted from standard strains of $L$ major (MRHO/IR/ 75/ER) and $L$ tropica (MHOM/IR/2002/Mash2). Distilled DNA-free water will be applied instead of extracted nucleic acid as a negative control. The amplicon sizes will be analysed on $1.5 \%$ agarose gel and visualised through ethidium bromide. Leishmania species will be discriminated, since the amplicon sizes differ between $L$ major and $L$ tropica (626 base pair [bp] and $800 \mathrm{bp}$, respectively). ${ }^{42}$ 


\section{Preparation of soluble Leishmania antigen}

A standard strain of $L$ major (MRHO/IR/75/ER) will be applied for soluble Leishmania antigen (SLA) preparation. Promastigot forms of this strain will be harvested up to stationary phase in RPMI 1640 (Gibco RL, Grand Island, NY) supplemented with $15 \%$ fetal bovine serum (FBS, Gibco, UK), $2 \mathrm{mM}$ glutamine (Invitrogen), $20 \mathrm{U}$ of penicillin (Gibco, UK) per $\mathrm{mL}$ and $20 \mathrm{mg}$ of streptomycin (Gibco, UK) per mL. For this aim, the parasite culture will be implemented in $26 \pm 1^{\circ} \mathrm{C}$ for five days. The harvested parasites will be washed four times through centrifugation ( $300 \mathrm{~g}$ for $30 \mathrm{~min}$ ) and pellet resuspension in sterile PBS at $\mathrm{pH}$ 7.2. The parasite concentration will be adjusted to $10^{9}$ parasites per $\mathrm{mL}$ by $100 \mathrm{mM}$ Tris-HCl, $\pm 1 \mathrm{mM}$ EDTA ( $\mathrm{pH} 8$ ), supplemented with $50 \mu \mathrm{g}$ of Leupeptin per $\mathrm{mL}$ and $1.6 \mathrm{mM}$ phenyl methyl sulfonyl fluoride (all from Sigma, St. Louis, MO, USA). To prevent denaturation of protein, a protease inhibitor cocktail (Sigma) will be added to the above-mentioned parasite suspension $(50 \mu \mathrm{L}$ in $1 \mathrm{~mL})$. Afterwards, the parasite bodies will be subjected to seven cycles of freezing and thawing at $-70^{\circ} \mathrm{C}$ and $37^{\circ} \mathrm{C}$, respectively. The procedure will be followed by sonication (10 times, each time $20 \mathrm{~s}$ in power $60 \%$ at $4^{\circ} \mathrm{C}$ ). Parasite suspension will be centrifuged at $30000 \times \mathrm{g}$ for $20 \mathrm{~min}$ at $4^{\circ} \mathrm{C}$ and the supernatant will be extracted. Then, the collected supernatant will be centrifuged again at $100000 \times \mathrm{g}$ for 4 hours at $4^{\circ} \mathrm{C}$. Importantly, the supernatant collection should exclude parasite lipid, which appears as a milky-colored layer on the top of the centrifuged supernatant. A dialysis pack (3500 dalton cut-off) filled with $10 \mathrm{mM} \mathrm{4-}$ (2-hydroxyethyl)-1-piperazineëthanesulfonic acid (HEPES) and sucrose $10 \%$ (all from Sigma) will be applied to exclude the protease inhibitor cocktail. The prepared antigen will be sterilised through a $0.22 \mu \mathrm{m}$ membrane filter. ${ }^{43}$

\section{Leishmanin skin test}

The leishmanin skin test (LST), or Montenegro skin test, is an in vivo assay, which demonstrates partial immunity against the Leishmania infection. All of the study participants will receive a suspension of killed promastigotes. This suspension is prepared in the Pastor Institute, Tehran, Iran. Every phial of the suspension includes PBS (1 cc), thiomersal $(0.1 \%)$, and killed $L$ major promastigotes $\left(6 \times 10^{6}\right.$ bodies of standard strain (MRHO/IR/75/ ER)). This suspension is kept in a refrigerator at $6^{\circ} \mathrm{C}$ up to the time of the application. For the administration, $0.1 \mathrm{~mL}$ of leishmanin suspension will be intradermally injected through a 27-gauge needle, in the palmar surface of the left forearm in every individual. Additionally, a placebo suspension, including PBS $(1 \mathrm{cc})$ and thiomersal $(0.1 \%)$, will be injected into the dorsal surface of the left arm. This placebo will also be produced by the same institute. Induration of delayed type hypersensitisation (DTH) resulting from the LST will be measured after 48 hours through a ballpoint pen. However, the induration measurement shall be repeated after 72 hours if there is no reaction. The outcome of the LST is negative unless the induration diameter is $>5 \mathrm{~mm}$. The positive results may also be classified as either normal positive or strongly positive, according to the diameter of induration (5-14 mm and $\geq 15 \mathrm{~mm}$, respectively). ${ }^{44}$

\section{Isolation of peripheral blood mononuclear cells}

In order to isolate peripheral blood mononuclear cells (PBMCs), heparinised human peripheral blood $(10 \mathrm{~mL})$ will be collected from every individual in one of the above-mentioned study groups. The collected blood will be diluted with an equal volume of sterile PBS (Cytomatin Gene Co, Isfahan, Iran) adjusted to $\mathrm{pH} 7.4$ and $260 \mathrm{~m}$ Osmo. This diluted blood will be gently layered on top of Ficoll-Hypaque (Lymphodex, Inno-Train, Germany) within sterile and Dnase/ Rnase-free conical tubes in an equal volume. These tubes will be centrifuged at $800 \times \mathrm{g}$ for $15 \mathrm{~min}$ at room temperature. After the centrifugation, the isolated PBMCs located in the second layer (out of the three formed layers) will be retrieved through a sterile Pasteur pipette. The collected layer will be washed twice in a sterile PBS $(10 \mathrm{~mL})$ through centrifugation (at $450 \times \mathrm{g}$ for $10 \mathrm{~min}$ ) and pellet resuspension. Washed PBMCs will be resuspended in RPMI 1640 (Gibco). To assess cell viability, the PBMCs suspension $(10 \mu \mathrm{L})$ will be dyed by trypan blue $(10 \mu \mathrm{L})$ hemocytometer-based technique. ${ }^{3846}$

\section{Cell culture}

Isolated PBMCs will be cultured at $1 \times 10^{6} / \mathrm{mL} /$ well in a 12-well plate. The culture medium will include RPMI 1640 supplemented with 10\% FBS (Gibco, UK), $2 \mathrm{mM}$ glutamine (Invitrogen), $20 \mathrm{U}$ of penicillin (Gibco, UK) per $\mathrm{mL}$ and $20 \mathrm{mg}$ of streptomycin (Gibco, UK). The cells will be stimulated with purified protein derivative (PPD), SLA, phytohemagglutinin (PHA) and recombinant IL-12 (rIL-12) in four treatments, as follows: (1) the first treatment will consist of SLA antigen $(5 \mu \mathrm{g} / \mathrm{mL})$; (2) the second treatment will consist of SLA $(5 \mu \mathrm{g} / \mathrm{mL})$ + rIL-12 $(10 \mathrm{U} / \mathrm{mL})$; (3) the third treatment will be stimulated through PHA $(10 \mathrm{mg} / \mathrm{mL})$; (4) the final treatment (control negative) will contain $12 \mu \mathrm{g}$ of PPD (Razi Institute, Karaj, Iran), as an irrelevant antigen (table 2). ${ }^{5}$ All of the plates will be incubated for 72 hours at $37^{\circ} \mathrm{C}$ under $5 \% \mathrm{CO}_{2} .{ }^{38} 46$

\section{Cytokine measurement}

After the plate incubation, the cell culture supernatant will be collected by centrifugation at $400 \mathrm{~g}$ for

Table 2 Stimulators of peripheral blood mononuclear cells (PBMCs) cultured in four different wells

\begin{tabular}{lllll}
\hline Well number & $\mathbf{1}$ & $\mathbf{2}$ & $\mathbf{3}$ & $\mathbf{4}$ \\
\hline Stimulator(s) & SLA & SLA+rlL-12 & PHA & PPD \\
\hline
\end{tabular}

PPD, purified protein derivative; PHA, phytohemagglutinin; rlL, recombinant interleukin; SLA, soluble Leishmania antigen. 
7 min. ${ }^{38} 46$ The supernatant will be analysed for cytokine measurements by an indirect form of ELISA using four commercial kits :(1) IFN- $\gamma$ ELISA kit eBiosciece (Ready-SET-Go!, USA catalog number\# 88-7316-22); (2) IL-12 p70 ELISA kit eBiosciece (Ready-SET-Go!, USA, catalog number $\neq 88-7126-22$ ); (3) CXCL-11 (San Diego, CA, CXCL-11 catalog number\# 443307) and (4) IL-17a ELISA kits Biolegend (San Diego, CA, catalog number\# 433917). Briefly, for each of the cytokines, a standard curve will be established using a twofold serial dilution of recombinant corresponding proteins ( $\mathrm{r}$ IFN- $\gamma$, rIL-12, rCXCL-11 and rIL-17a). Additionally, an appropriate dilution factor of every sample will be determined if the optical density falls outside of the corresponding standard curve. All of the data will be calculated through computer-based curve-fitting software when the mean absorbance for each set of duplicate standards, controls and samples is determined.

\section{Flow cytometry of IL-12Rß1 (CD212)}

To assess whether there is an association between IL-12R $\beta 1$ expression and pro-inflammatory cytokines (IL-12, IFN- $\gamma$, IL-17a and CXCL-11), a flow cytometry analysis of IL-12R $\beta 1$ will be performed. IL-12R $\beta 1$ has a low expression on unstimulated $\mathrm{T}$ cells and is highly expressed on activated T cells. Hence, we aim to restimulate PHA-treated cells (as was described in the Cell culture section) with recombinant IL-2(r-IL2). ${ }^{46}$

\section{Restimulation of PHA-treated cells}

PHA-treated cells will be pelleted and recultured in a density of $2 \times 10^{5}$ cells $/ \mathrm{mL}$ for 48 hours at $37^{\circ} \mathrm{C}$ under an atmosphere containing $5 \% \mathrm{CO}_{2}$. These cells will be restimulated by human rIL-2 (50 IU $/ \mathrm{mL}$; R\&D system) in Panserin 401 medium (Pan Biotech) with 10\% FBS and 2 mM L-glutamine (Gibco). ${ }^{46}$

\section{Cell preparation for flow cytometry and flow cytometry analysis}

PHA and rIL-2-treated cells will be pelleted and washed with PBS. Afterwards, these cells will be incubated with either an IL-12R $\beta 1$ specific mouse antihuman IgG1 monoclonal antibody (BD Biosciences, USA, cat. no\# 556065 ) or its appropriate isotype antibody (BD Biosciences, USA, cat. no\# 555749) on ice for $20 \mathrm{~min}$ (all of the antibodies are fluorolabeled with phycoerythrin $(\mathrm{PE}))$. The antibody-incubated cells will be washed twice with a blocking solution (2\% FBS in PBS). Finally, cell analysis will be performed through a FACScan machine, using Cellquest software (Becton Dickinson San Jose, CA). ${ }^{46}$

\section{Genetic analysis}

RNA extraction

RNA will be extracted from cells cultured in the presence of one of the above-mentioned antigens (SLA $(5 \mu \mathrm{g} / \mathrm{mL})$, PHA $(10 \mathrm{mg} / \mathrm{mL})$ or PPD $(12 \mu \mathrm{g} / \mathrm{mL}))$ using a total RNA extraction kit (Jena Bioscience,
GmbH, Jena, Germany) according to the manufacturer's instructions. To avoid genomic contamination, the extracted RNA will be treated with RNA-free DNAse I (10 U/L; cat no. EN0525, Fermentas, St. Leon-Rot, Germany) at $22^{\circ} \mathrm{C}$ for $15 \mathrm{~min}$. This enzyme will be inactivated through EDTA $(2 \mu \mathrm{L}$ of $7.5 \mathrm{mM})$ at $65^{\circ} \mathrm{C}$ for $10 \min ^{47}$

\section{cDNA synthesis}

In the first step, the purity and concentration of the extracted RNA will be assessed through the absorbance at $260 \mathrm{~nm}$ (260A), $280 \mathrm{~nm}(280 \mathrm{~A})$ and $230 \mathrm{~nm}$ (230A) using a NanoDrop ND-1000 spectrophotometer (Thermo Fisher Scientific, Waltham, MA). ${ }^{48}$ Highly purified $5 \mu \mathrm{g}$ of mRNA (optical density (OD) ratios: 260/ $280=1.92 .0$ and $260 / 230=2.02 .2$ ) will be reverse transcribed using a Reverta-L kit (Central Institute of Epidemiology, Moscow, Russia) through oligo-dT.

\section{Real-time PCR for CXCR-3 and IL-17a expression}

Primer designing for real-time PCR All of the primers aiming for either target (CXCR-3 and IL-17a) or reference (glyceraldehyde-3-phosphate-dehydrogenase (GAPDH)) gene amplification were designed according to GenBank sequence information (table 3). ${ }^{49} 50$

Real-time PCR protocol Quantification of gene expression will be performed through a comparative $\mathrm{C}_{\mathrm{T}}$ method in a commercial real-time thermocycler (ABI Prism 7000) in accordance with the manufacturer's instructions. For this aim, $1 \mu \mathrm{L}$ of our cDNA solution will be mixed with $19 \mu \mathrm{L}$ of a master mix: $20 \mathrm{pMol}$ of every primer, optimised concentration of $\mathrm{MgCl}_{2}$ (ranging from 1-8 $\mathrm{mM}$ ) and $2 \mu \mathrm{L}$ of SYBR Green I master mix (Roche Burgess Hill, UK). Real-time PCR conditions will be set at: $95^{\circ} \mathrm{C}$ for $3 \mathrm{~min}$ (as an initial denaturation step), followed by 40 cycles of $95^{\circ} \mathrm{C}$ for $10 \mathrm{~s}$. After the implementation of optimal primer annealing temperature ranging from 50 to $60^{\circ} \mathrm{C}$ for $30 \mathrm{~s}$ and primer extension at $72^{\circ} \mathrm{C}$ for $45 \mathrm{~s}$, the florescent amplitude will be measured for a period of $1 \mathrm{~s}$. Final extension step will be performed at $72^{\circ} \mathrm{C}$ for $5 \mathrm{~min}$. Besides this, a melting curve, which potentially ranges from 60 to $99^{\circ} \mathrm{C}$, will be acquired (heating rate: $0.1^{\circ} \mathrm{C} / \mathrm{s}$ ) to ensure uniformity of PCR products. ${ }^{51}$

Moreover, to detect potential genomic contamination, negative control, which will contain non-reverse transcribed RNA and GAPDH primers, will be included in each run (table 3).

Relative quantification of gene expression through real-time PCR To quantify the gene expressions, the amount of CXCR-3, IL-17a expressions will be normalised to GAPDH cDNA and normalised in accordance with unstimulated cells (calibrator). This quantification will be calculated by $2^{-\Delta \Delta \mathrm{CT}}$ where $\Delta \Delta \mathrm{Ct}=(\mathrm{CT}$ target CT reference) calibrator_(CT target_CT reference) sample. This calculation is valid when the amplification 
Table 3 Sequences of oligonucleotide primers for real-time PCR

\begin{tabular}{|c|c|c|c|c|c|c|}
\hline \multirow[b]{2}{*}{ Gene } & \multirow[b]{2}{*}{ Primer sequence(forward and reverse $(5 /-3 /))$} & \multicolumn{2}{|l|}{ Length } & \multirow[b]{2}{*}{ Tm } & \multirow[b]{2}{*}{ CG\% } & \multirow[b]{2}{*}{ Accession number } \\
\hline & & Primer & Product & & & \\
\hline \multirow{2}{*}{ CXCR-3 } & GGTGCCCTCTTCAACATCAAC & 21 & 90 & 44.3 & 52.4 & NC_000023 \\
\hline & GGTGGCATGAACTATGTTCAGGTA & 24 & & 46.5 & 45.8 & \\
\hline \multirow{2}{*}{ IL-17a1 } & CCCCTAGACTCAGGCTTCCT & 20 & 135 & 42.7 & 60 & NC_000006 \\
\hline & TCAGCTCCTTTCTGGGTTGT & 20 & & 41.9 & 50 & \\
\hline \multirow[t]{2}{*}{ IL-17a2 } & GAAGGCAGGAATCACAATC & 19 & 1461 & 36.8 & 47.4 & NC_000006 \\
\hline & GCCTCCCAGATCACAGA & 17 & & 34 & & \\
\hline \multirow[t]{2}{*}{ GAPDH } & ACCCAGAAGACTGTGGATGG & 20 & 200 & 36.8 & 58.8 & NC_000012 \\
\hline & TTCTAGACGGCAGGTCAGGT & 20 & & 34 & 47.4 & \\
\hline
\end{tabular}

efficiencies of all genes are roughly identical at or $>90 \%{ }^{5152}$

\section{IL-12B and IL-12RB1 exon sequencing}

Six coding exons of the IL-12B gene of non-healing patients will be sequenced in the following conditions: ${ }^{1}$ lack of IFN- $\gamma$ production in the SLA-simulated well (first well); (2) retrieval of IFN- $\gamma$ production in the presence of SLA and rIL-12 (second well). On the other hand, 16 coding exons of IL-12RB1 will be sequenced, providing IFN- $\gamma$ will not be appropriately produced in SLA-stimulated and IL-12-added wells (first and second well). For this reason, PCR amplification will be implemented in two different conditions, as follows:

IL-12B1 PCR amplification PCR amplification will be performed in a reaction volume $(25 \mu \mathrm{L})$, which consists of $1.25 \mathrm{U}$ of Taq DNA polymerase (Fermentase), $0.4 \mathrm{~mm}$ dNTPs, $2.5 \mu \mathrm{L}$ of $10 \mathrm{X}$ reaction buffer, $2.5 \mathrm{mM} \mathrm{MgCl}_{2}$, $20 \mathrm{ng}$ of cDNA and $10 \mu \mathrm{L}$ of appropriate primers (table 4) ${ }^{53}$ This amplification protocol consists of an initial denaturation at $95^{\circ} \mathrm{C}$ for $5 \mathrm{~min}$; 36 cycles of denaturation at $95^{\circ} \mathrm{C}$ for $30 \mathrm{~s}$, annealing at $58^{\circ} \mathrm{C}$ for $30 \mathrm{~s}$, extension at $72^{\circ} \mathrm{C}$ for $150 \mathrm{~s}$ and the final extension at $72^{\circ} \mathrm{C}$ for 7 min. ${ }^{53}$

Exon amplification of IL-12RB1 gene $20 \mathrm{ng}$ of cDNA will be amplified in a $25 \mu \mathrm{L}$ of reaction mixture: $2.5 \mu \mathrm{L}$ of $10 \mathrm{X}$ reaction buffer, $1 \mu \mathrm{L}$ of $2 \mathrm{mM} \mathrm{MgCl}_{2}, 0.5 \mu \mathrm{L}$ of $25 \mathrm{mM}$
dNTP, $0.5 \mu \mathrm{L}$ of $10 \mathrm{mM}$ appropriate primer (table 5), $1.25 \mathrm{U}$ of Taq DNA polymerase (Fermentase) and $2.5 \mu \mathrm{L}$ of $50 \%$ dimethyl sulfoxide (DMSO) solution. ${ }^{46}$ The PCR condition includes an initial denaturation at $95^{\circ} \mathrm{C}$ for 5 min; 38 cycles of denaturation at $94^{\circ} \mathrm{C}$ for $45 \mathrm{~s}$, annealing at $60^{\circ} \mathrm{C}$ for $45 \mathrm{~s}$, extension at $72^{\circ} \mathrm{C}$ for $45 \mathrm{~s}$ and the final extension at $72^{\circ} \mathrm{C}$ for $7 \mathrm{~min}$.

The amplicon quality will be checked by way of electrophoresis on $1 \%$ agarose gel. Afterwards, bidirectional sequencing will be implemented on an ABI 3130 automated sequencer (XL genetic analyser) through the BigDye terminator V.3.1. ${ }^{46}$

\section{Statistical analysis}

All data will be analysed using SPSS V.20 (SPSS, Chicago, USA). Categorical variables will be reported as frequency and percentage, while continuous variables will be described as mean and SD or median (IQR), as appropriate. Repeated measures analysis of variance (ANOVA), with five between group factors and three within group measures, will be applied to compare different cytokine levels between and within groups, respectively. Participant classification in low IFN- $\gamma$ or high IFN- $\gamma$ categories will be based on a receiver operating characteristics curve (ROC) analysis. Additionally, sensitivity and specificity of various levels of IFN- $\gamma$ for determining the best cut-off point will be evaluated. The IL-12R $\beta 1$ expression will be compared through $\chi^{2}$ or Fisher exact test.

Table 4 Sequences of oligonucleotide primers for PCR amplification of IL-12B coding exons

\begin{tabular}{|c|c|c|c|c|c|c|}
\hline \multirow[b]{2}{*}{ Covering exons } & \multirow[b]{2}{*}{ Primer sequence(forward and reverse (5/-3/)) } & \multicolumn{2}{|l|}{ Length } & \multirow[b]{2}{*}{ Tm } & \multirow[b]{2}{*}{ CG\% } & \multirow[b]{2}{*}{ Accession number } \\
\hline & & Primer & Product & & & \\
\hline \multirow[t]{2}{*}{ Exon 2,3,4 } & GACTCTCCGTCCTGCCCA & 18 & 493 & 60.68 & 66.7 & NC_000005 \\
\hline & GACACTGAATGTCAAATCAG & 20 & & 52.22 & 40 & \\
\hline \multirow[t]{2}{*}{ Exon $5,6,7$} & TCTGGACGTTTCACCTGCTG & 20 & 656 & 60.25 & 55 & NC_000006 \\
\hline & GTCTATTCCGTTGTGTCTTT & 20 & & 53.28 & 40 & \\
\hline \multirow[t]{2}{*}{ Exon 8} & CATCTGTGCCCTGCAGTTAG & 20 & 1328 & 58.62 & 55 & NC_000006 \\
\hline & AAGAGTTTTTATTAGTTC & 18 & & 41.41 & 22 & \\
\hline
\end{tabular}

IL, interleukin; $\mathrm{Tm}$, melting temperature. 
Table 5 Sequences of oligonucleotide primers for PCR amplification of IL-12RB1 coding exons

\begin{tabular}{|c|c|c|c|c|c|c|}
\hline \multirow[b]{2}{*}{ Covering exons } & \multirow{2}{*}{$\begin{array}{l}\text { Primer sequence(forward } \\
\text { and reverse }(5 /-3 /))\end{array}$} & \multicolumn{2}{|l|}{ Length } & \multirow[b]{2}{*}{$\mathrm{Tm}$} & \multirow[b]{2}{*}{ CG\% } & \multirow[b]{2}{*}{ Accession numbe } \\
\hline & & Primer & Product & & & \\
\hline \multirow[t]{2}{*}{ Exon: $1,2,3,4,5,6,7,8$} & TCGCAGGTGGCAGAGAGG & 18 & 845 & 61.39 & 66.67 & XM_011527977 \\
\hline & GCTGGGTTGGCTGCTCTTT & 19 & & 60.91 & 57.89 & \\
\hline \multirow[t]{2}{*}{ Exon: $6,7,8,9,10,11$} & CGGACACCCAGCAGCCCA & 18 & 801 & 64.71 & 72.22 & XM_011527976 \\
\hline & CAGGACCGTAGACCACAAG & 19 & & 57.19 & 57.89 & \\
\hline \multirow[t]{2}{*}{ Exon: $10,11,12,13,14,15,16,17$} & CATTGAATGGCAGCCTGTG & 19 & 903 & 57.27 & 52.63 & XM_011527975 \\
\hline & GAGTCACTCАСССТСТСТG & 19 & & 56.18 & 57.89 & \\
\hline
\end{tabular}

\section{DISCUSSION}

Low amounts of IFN- $\gamma$ production have been previously shown in some patients afflicted by non-healing leishmaniasis. ${ }^{37} 3854$ On the other hand, some studies have determined genetic defects, which impede IFN- $\gamma$ production, predisposing some patients to intracellular microorganisms. For example, IL-12B and IL-12RB1 mutations are considered as two major components, which induce increased susceptibility to non-tuberculous mycobacteria (NTM) species. $^{55}$ Neither investigation, however, has evaluated genetic defects, which potentially lead to NHCL.

The current study could discriminate between IL-12B and IL-12RB1 mutations through dichotic responses induced by rIL-12. Indeed, NHCL cases may be afflicted by IL-12B mutation(s) if the PBMCs of these patients can retrieve IFN- $\gamma$ production in SLA+rIL-12 wells (table 2). However, IL-12B mutation(s) will be further assessed and analysed by IL-12B sequencing. Moreover, there will be a probability of IL-12R $\beta 1$ deficiency unless IFN- $\gamma$ will be sufficiently produced in the presence of rIL-12. We will analyse IL-12R $\beta 1$ deficiency by flow cytometry, and we will also assess IL-12RB1 mutation(s) through sequencing. It is anticipated that the outcome of the current study could identify IL-12B and IL-12RB1 mutations, which lead to persistent lesions of CL.

In addition, our expected results can pave the way for further immunotherapy of Leishmania lesions. Indeed, scientists can provide NHCL cases with appropriate immunotherapy when the pathophysiology of the persistent lesions is clearly described. For example, identification of NHCL cases afflicted by IL-12B or IL-12RB1 mutations suggest animal modelling, and even future clinical trials, aiming to apply rIL-12 or rIFN- $\gamma$ for the treatment of the chronic lesions. Furthermore, our expected results will reveal an association between NHCL and pro-inflammatory cytokines (IFN- $\gamma$, IL-12, IL-17a, CXCL-11), as well as CXCR-3 expression.

\section{DISSEMINATION}

Information regarding the nature of the research project will be clearly described for all of the participants in written and verbal format. Afterwards, informed consent will be obtained from every participant, or their guardians, by trained medical staff. The informed consent will assure the patients that they can leave the study at their convenience.

Biological samples will be identified through a code number and the medical data of participants will be analysed anonymously. Paper-based data of the participants will be kept in a locked cabinet at the Acquired Immunodeficiency Research Center, and electronic information will be stored on a password-protected computer.

The final results will be disseminated through peerreviewed journals and scientific conferences. All of the reports will be submitted to the project funder.

\section{Author affiliations}

${ }^{1}$ Faculty of Veterinary Science, Department of Pathobiology, Bu-Ali Sina University, Hamedan, Iran

${ }^{2}$ Acquired Immunodeficiency Research Center, Isfahan University of Medical Sciences, Isfahan, Iran

${ }^{3}$ Skin Diseases and Leishmaniasis Research Center, Isfahan University of Medical Sciences, Isfahan, Iran

${ }^{4}$ Faculty of Sciences, Department of Biology, University of Isfahan, Isfahan, Iran

${ }^{5}$ Skin and Stem Cell Research Center, Tehran University of Medical Sciences,

Tehran, Iran

${ }^{6}$ Department of Epidemiology and Biostatistics, School of Public Health, Isfahan University of Medical Sciences, Isfahan, Iran

Contributors HR, RS, MM, RT, AA, SHZ, MAN, FJ and AF developed the original proposal. HR, MM and RS prepared the first draft of the present manuscript with the support of all authors. All authors read and approved the final manuscript.

Funding This research was financially supported by Bu-Ali Sina University, Hamedan, Iran.

Competing interests None declared.

Ethics approval This study has been approved by Ethical Committee of Hamedan University of Medical Sciences (HUMS) (Code: IR.UMSHA. REC.1395.120).

Provenance and peer review Not commissioned; externally peer reviewed.

Data sharing statement Final results will be disseminated through peer-reviewed journals and scientific conferences.

Open Access This is an Open Access article distributed in accordance with the Creative Commons Attribution Non Commercial (CC BY-NC 4.0) license, which permits others to distribute, remix, adapt, build upon this work noncommercially, and license their derivative works on different terms, provided the original work is properly cited and the use is non-commercial. See: http:// creativecommons.org/licenses/by-nc/4.0/ 


\section{REFERENCES}

1. Rezvan H, Moafi M, eds. An overview on Leishmania vaccines: a narrative review article. Urmia, IranmVeterinary Research Forum, Faculty of Veterinary Medicine, Urmia University, 2015.

2. Dujardin J-C, Decuypere S. Epidemiology of leishmaniasis in the time of drug resistance. Springer, 2013.

3. Maran N, Gomes PS, Freire-de-Lima L, et al. Host resistance to visceral leishmaniasis: prevalence and prevention. Expert Rev Anti Infect Ther 2016;14:435-42.

4. Eiras DP, Kirkman LA, Murray HW. Cutaneous leishmaniasis: current treatment practices in the USA for returning travelers. Curr Treat Options Infect Dis 2015;7:52-62.

5. Baptista C, Miranda Lde F, Madeira Mde F, et al. In vitro sensitivity of paired Leishmania (viannia) braziliensis samples isolated before meglumine antimoniate treatment and after treatment failure or reactivation of cutaneous leishmaniasis. Dis Markers 2015;2015:943236

6. Wollina U, Koch A, Schönlebe J, et al. Non-healing facial lesions: cutaneous old world leishmaniasis in dresden. J Biol Regul Homeost Agents 2015;29:(1 Suppl):99-102.

7. Rahim A, Moniruzzan M, Hassan R, et al. Cutaneous leishmaniasis in a Bangladeshi adult: a case report. Bangladesh J Med 2015;25:78-80.

8. Kroidl A, Kroidl I, Bretzel G, et al. Non-healing old world cutaneous leishmaniasis caused by $\mathrm{L}$. infantum in a patient from Spain. BMC Infect Dis 2014;14:206.

9. Barry MA, Koshelev MV, Sun GS, et al. Cutaneous leishmaniasis in Cuban immigrants to Texas who traveled through the Darién Jungle, Panama. Am J Trop Med Hyg 2014;91:345-7.

10. Gurung $P$, Karki R, Vogel $P$, et al. An NLRP3 inflammasometriggered Th2-biased adaptive immune response promotes leishmaniasis. J Clin Invest 2015;125:1329.

11. Li J, Liu D, Mou Z, et al. Deficiency of prolactin-inducible protein leads to impaired Th1 immune response and susceptibility to Leishmania major in mice. Eur J Immunol 2015;45:1082-91.

12. Thakur AK, Purkait B, Jamal F, et al. Direct evidence for role of anti-saliva antibodies against salivary gland homogenate of $P$. argentipes in modulation of protective Th1-immune response against Leishmania donovani. Cytokine 2016;86:79-85.

13. Honda JR, Knight V, Chan ED. Pathogenesis and risk factors for nontuberculous mycobacterial lung disease. Clin Chest Med 2015;36:1-11

14. Schepers K, Schandené L, Bustamante J, et al. IL-12R $\beta 1$ deficiency and disseminated mycobacterium tilburgii disease. J Clin Immunol 2013;33:1285-8.

15. Prando C, Samarina A, Bustamante J, et al. Inherited IL-12p40 deficiency: genetic, immunological, and clinical features of 49 patients from 30 kindreds. Medicine (Baltimore) 2013;92:109-22.

16. Sanal O, Turkkani G, Gumruk F, et al. A case of interleukin-12 receptor $\beta-1$ deficiency with recurrent Leishmaniasis. Pediatr Infect Dis J 2007;26:366-8.

17. van de Vosse E, Haverkamp MH, Ramirez-Alejo N, et al. IL-12R 31 deficiency: mutation update and description of the IL12RB1 variation database. Hum Mutat 2013;34:1329-39.

18. Nascimento M, Carregaro V, Lima D, et al. IL-17 has a critical role to promote protection against Leishmania infantum infection (P3011). $J$ Immunol 2013;190:55.6.

19. Nascimento MS, Albuquerque TD, Nascimento AF, et al. Impairment of interleukin-17A expression in canine visceral leishmaniosis is correlated with reduced interferon- $\gamma$ and inducible nitric oxide synthase Expression. J Comp Pathol 2015;153:197-205.

20. Terrazas $\mathrm{C}$, Varikuti S, Kimble J, et al. IL-17A promotes susceptibility during experimental visceral leishmaniasis caused by Leishmania donovani. FASEB J 2016;30:1135-43.

21. Sheel M, Beattie L, Frame TC, et al. IL-17A-producing $\gamma \delta$ T cells suppress early control of parasite growth by monocytes in the liver. $J$ Immunol 2015;195:5707-17.

22. Groom JR, Richmond J, Murooka TT, et al. CXCR3 chemokine receptor-ligand interactions in the lymph node optimize CD4+ T helper 1 cell differentiation. Immunity 2012;37:1091-103.

23. Oghumu S, Stock JC, Varikuti S, et al. Transgenic expression of CXCR3 on T cells enhances susceptibility to cutaneous Leishmania major infection by inhibiting monocyte maturation and promoting a Th2 response. Infect Immun 2015;83:67-76.

24. Roebrock K, Sunderkötter $\mathrm{C}$, Münck NA, et al. Epidermal expression of I-TAC (Cxcl11) instructs adaptive Th2-type immunity. FASEB J 2014;28:1724-34

25. Bazargan Harandi N, Hosseininasab A, Marashi SM, et al. Prevalence of primary immunodeficiency diseases in Kerman, Southeast of Iran. Int J Pediatr 2015;31):601-8.
26. Najafian B, Shahverdi E, Konjedi MA, et al. Maple syrup urine disease: incidence and related factors in infants 2008-2015, Tehran, Iran. Galen Med J 2015;4:164-8.

27. Sagvand $B$, Mirminachi $B$, Abolhassani $H$, et al. IgG anti-IgA antibodies in paediatric antibody-deficient patients receiving intravenous immunoglobulin. Allergol Immunopathol (Madr) 2015;43:403-8.

28. Nabavi M, Arshi S, Bemanian M, et al. Long-term follow-up of ninety eight Iranian patients with primary immune deficiency in a single tertiary centre. Allergol Immunopathol (Madr) 2016;44:322-30.

29. Saadat M, Tajbakhsh K. Prevalence of consanguineous marriages in west and south of Afghanistan. J Biosoc Sci 2013;45:799-805.

30. Hoseini SG, Javanmard SH, Hejazi SH, et al. Comparison of immune regulatory factors in acute and chronic lesions of cutaneous leishmaniasis due to Leishmania major. J Res Med Sci 2014;19 (Suppl 1):S36-40.

31. Pazoki H, Fakhar M, Rasooli A, et al. Lupoid leishmaniasis among the known cases of cutaneous leishmaniasis in Herat Province western Afghanistan. J Infect Public Health 2016;9:557-63.

32. Tolouei S, Hejazi SH, Ghaedi K, et al. Identification of Leishmania isolates from healing and nonhealing cutaneous leishmaniasis patients using internal transcribed spacer region PCR. Jundishapur J Microbiol 2014;7:e9529.

33. Tolouei S, Ghaedi K, Khamesipour A, et al. IL-23 and IL-27 levels in macrophages collected from peripheral blood of patients with healing vs non-healing form of cutaneous leishmaniasis. Iran J Parasitol 2012;7:18.

34. Sharifi I, Fekri AR, Aflatoonian MR, et al. Leishmaniasis recidivans among school children in Bam, South-east Iran, 1994-2006. Int $J$ Dermatol 2010;49:557-61.

35. Hajjaran $\mathrm{H}$, Mohebali M, Akhavan AA, et al. Unusual presentation of disseminated cutaneous leishmaniasis due to Leishmania major: case reports of four Iranian patients. Asian Pac J Trop Med 2013;6:333-6.

36. Solomon M, Greenberger S, Baum S, et al. Unusual forms of cutaneous leishmaniasis due to Leishmania major. J Eur Acad Dermatol Venereol 2016;30:1171-5.

37. Habibi GR, Khamesipour A, McMaster WR, et al. Cytokine gene expression in healing and non-healing cases of Cutaneous Leishmaniasis in Response to In vitro Stimulation with Recombinant gp63 Using semi-quantitative RT-PCR. Scand J Immunol 2001:54:414-20.

38. Ajdary S, Alimohammadian $\mathrm{MH}$, Eslami MB, et al. Comparison of the immune profile of nonhealing cutaneous leishmaniasis patients with those with active lesions and those who have recovered from infection. Infect Immun 2000;68:1760-4.

39. Fletcher $\mathrm{RH}$, Fletcher SW, Fletcher GS. Clinical epidemiology: the essentials. 2012, 5th edn. Lippincott Williams \& Wilkins.

40. Mouttaki T, Morales-Yuste M, Merino-Espinosa G, et al. Molecular diagnosis of cutaneous leishmaniasis and identification of the causative Leishmania species in Morocco by using three PCR-based assays. Parasit Vectors 2014;7:420.

41. Ladopoulos $\mathrm{T}$, Ntais $\mathrm{P}$, Tsirigotakis $\mathrm{N}$, et al. The proliferation potential of promastigotes of the main Leishmania species of the old world in NNN culture medium prepared using blood of four different mammals. Exp Parasitol 2015;157:124-7.

42. Kheirandish F, Sharafi A, Kazemi B, et al. Identification of Leishmania species using PCR assay on giemsa-stained slides prepared from cutaneous leishmaniasis patients. Iran J Parasitol 2013;8:382.

43. Mehravaran A, Jaafari MR, Jalali SA, et al. Cationic immune stimulating complexes containing soluble Leishmania antigens: preparation, characterization and in vivo immune response evaluation. Iran J Immunol 2015;12:274-87.

44. Momeni Boroujeni A, Aminjavaheri M, Moshtaghian B, et al. Reevaluating leishmanin skin test as a marker for immunity against cutaneous leishmaniasis. Int J Dermatol 2013;52:827-30.

45. Gadisa E, Custodio E, Cañavate C, et al. Usefulness of the rK39-immunochromatographic test, direct agglutination test, and leishmanin skin test for detecting asymptomatic Leishmania infection in children in a new visceral leishmaniasis focus in Amhara State, Ethiopia. Am J Trop Med Hyg 2012;86:792-8.

46. de Beaucoudrey L, Samarina A, Bustamante J, et al. Revisiting human IL-12R $\beta 1$ deficiency: a survey of 141 patients from 30 countries. Medicine (Baltim) 2010;89:381.

47. Woo HG, Wang XW, Budhu A, et al. Association of TP53 mutations with stem cell-like gene expression and survival of patients with hepatocellular carcinoma. Gastroenterology 2011;140:1063-70.e8.

48. Kalmar A, Wichmann B, Galamb O, et al. Gene expression analysis of normal and colorectal cancer tissue samples from fresh frozen and matched formalin-fixed, paraffin-embedded (FFPE) specimens 
after manual and automated RNA isolation. Methods 2013;59: S16-S9.

49. Kurata R, Fujita F, Oonishi K, et al. Inhibition of the CXCR3-mediated pathway suppresses ultraviolet B-induced pigmentation and erythema in skin. Br J Dermatol 2010;163:593-602.

50. Peters TL, McClain KL, Allen CE. Neither IL-17A mRNA nor IL-17A protein are detectable in Langerhans cell histiocytosis lesions. Mol Ther 2011;19:1433-9.

51. Baine MJ, Mallya K, Batra SK. Quantitative real-time PCR expression analysis of peripheral blood mononuclear cells in pancreatic cancer patients. Methods Mol Biol 2013;980:157-73.
52. Arya M, Shergill IS, Williamson M, et al. Basic principles of real-time quantitative PCR. Expert Rev Mol Diagn 2014;5:209-19.

53. Picard C, Fieschi C, Altare F, et al. Inherited interleukin-12 deficiency: IL12B genotype and clinical phenotype of 13 patients from six kindreds. Am J Hum Genet 2002;70:336-48.

54. Shahi M, Mohajery M, Shamsian SAA, et al. Comparison of Th1 and Th2 responses in non-healing and healing patients with cutaneous leishmaniasis. Rep Biochem Mol Biol 2013;1:43.

55. Law S-T, Chiu S-C, Li KK. Intestinal tuberculosis complicated with perforation during anti-tuberculous treatment in a 13-year-old girl with defective mitogen-induced IL-12 production. J Microbiol Immunol Infect. 2014:47:441-6. 